\title{
FRAUDE Y REVISIÓN POR PARES
}

Javier Jiménez*

Más de cien artículos científicos retirados por fraude son una llamada de atención: o cambiamos el sistema o tendremos problemas

Wás de cien papers (artículos científicos) acaban de ser retractados los autores fingieron el proceso de revisión de pares. No es un hecho aislado: el año pasado cayeron otros 58 artículos científicos de los que 25 fueron de la misma revista.

Pero, siendo sinceros, esto es solo una gota en el océano de problemas que arrastra la ciencia contemporánea. Hoy las debilidades del sistema de publicación científica afectan a la investigación del cáncer, pero si no buscamos una solución pronto las consecuencias pueden ser mucho más graves.

\section{LA PLAGA DE LOS ARTÍCULOS RETRACTADOS}

Basta echar un ojo a Retraction Watch para ver que cada día se retractan numerosos artículos en todo el mundo. Distinguir entre fraudes, malas prácticas y errores se está convirtiendo en todo un problema. Los ánimos están tan caldeados que muchos investigadores llegan a decir abiertamente que tienen miedo de que un error se convierta en su "tumba profesional".

Este caso es llamativo no solo por el número de artículos, sino por la forma en que lo han hecho. Para publicar un artículo científico se tiene que pasar por una "revisión de pares" anónima. Es decir, el texto

\footnotetext{
* Editor de ciencia de las revistas electrónicas Xataka y Magnet. Fecha de recepción: 24-04- 2017, fecha de aceptación: 24-04- 2017. Sugerencia de citación: Jiménez J. "Fraude y revisión por pares”, Revista de Economía Institucional 19, 36, 2017, pp. 367-369. DoI: https://doi.org/10.18601/01245996.v19n36.21.
} 
se envía a otros expertos del área para que vean si está bien hecho, si es interesante y si es novedoso. El problema es que las revisiones de artículos están mal gestionadas.

El sistema se basa en tener a superexpertos trabajando sin remuneración para revistas que suelen ganar mucho dinero. Algo que, quién lo iba a decir, no funciona todo lo bien que nos gustaría. En los últimos años, los investigadores pueden sugerir revisores para un trabajo concreto. Esto es así porque el nivel técnico de muchas de las investigaciones es tan alto que solo hay un grupo reducido de especialistas con suficientes conocimientos para revisar el trabajo; pero también porque las revistas están muy desesperadas por encontrar revisores.

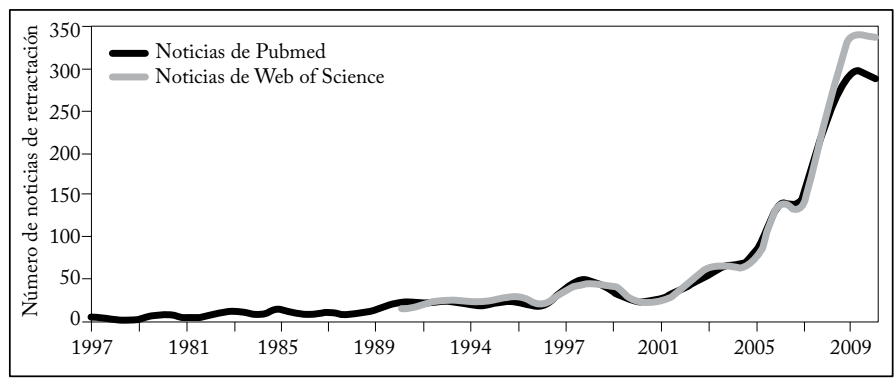

\section{EL MISTERIOSO CASO DEL REVISOR FANTASMA}

Lo curioso del caso no es que se haya creado un cártel o un colegio invisible. Es decir, no se trata de un grupo de investigadores que "trapicheaban" con las revisiones de sus propios artículos. El fraude ha consistido, directamente, en inventarse investigadores que no existían, con correos y cargos falsos en universidades de todo el mundo.

Como explicaba la editora de la revista Research Integrity and Peer Review Elizabeth Wager en Ars Technica, los revisores falsos "sabían cómo eran las revisiones y las hacían plausibles". Sin embargo, no fueron plausibles en todo el proceso de revisión.

Tanto es así que los pillaron por puntuales. Las revisiones habituales no suelen llegar en fecha y suelen retrasar todo el proceso de publicación científica. Los revisores falsos, en cambio, siempre eran puntuales. Algo demasiado bueno para ser verdad.

\section{LA PROFESIONALIZACIÓN DEL FRAUDE}

Según la investigación, el problema ha ido creciendo porque el fraude se ha "profesionalizado". Según parece, el origen del problema no está 
solo en los investigadores, sino en algunos servicios que usan de forma asidua los grupos de investigación que no son angloparlantantes.

Según parece, hay ciertas empresas de traducción y de servicios editoriales que habían convertido la revisión fraudulenta en un servicio más. Muchas veces sin que ni los investigadores lo supieran.

Ante las sospechas, Springer, la antigua editora de la revista, decidió hacer un análisis más completo de todo lo que estaba pasando en la revista. Ahí descubrieron nuevos revisores falsos y, por ahora, han caído 107 papers.

\section{UN PROBLEMA DE FONDO}

Hace unos días, Marcus Banks en Slate defendía que necesitábamos un GitHub para la investigación académica. Es una reflexión que se enmarca en un problema que viene de largo: el paper ha sido, durante siglos, una de las vías más exitosas para comunicar ciencia. En las últimas décadas, ha dejado atrás a libros y monográficos.

Sin embargo, es un sistema demasiado estático y poco versátil. Como decía Banks, el lamentable y fraudulento estudio de Wakefield en el que relacionaba vacunas y autismo se publicó en 1998. Pero, aunque se supo casi de inmediato que era falso, Lancet, la revista que lo publicó, solo lo retractó completamente en 2010.

Daniel Lakens, profesor de psicología experimental en la Universidad Tecnológica de Eindhoven y uno de los "activistas de la replicabilidad" más conocidos de los últimos años, fue mucho más allá. Para él, ha llegado el momento en que las entradas de un blog tienen más calidad científica que muchos artículos científicos. Lakens lo tiene claro: son más abiertos, más dinámicos, más innovadores y se corrigen mejor.

Lakens siempre está a mitad de camino entre el argumento interesante y la boutade, pero sin duda ahí hay un problema importante. Todo el sistema de la ciencia contemporánea se fundamenta sobre una base bibliométrica que atraviesa serios problemas, pero que, como podemos ver, no sabemos cómo solucionar. Los próximos años van a ser fundamentales... y muy divertidos. 